\title{
Precision grinding for rapid fabrication of segments for extremely large telescopes using the Cranfield $\mathrm{BoX}^{\circledR}$
}

\author{
Xavier Tonnellier* ${ }^{\mathrm{a}, \mathrm{b}}$, Paul Morantz ${ }^{\mathrm{a}, \mathrm{b}}$, Paul Shore ${ }^{\mathrm{a}, \mathrm{b}}$ and Paul Comley ${ }^{\mathrm{a}, \mathrm{b}}$ \\ ${ }^{a}$ Cranfield University Precision Engineering Centre, Cranfield University, MK43 OAL, UK; \\ ${ }^{\mathrm{b}}$ Ultra Precision and Structured Surfaces Centre, Cranfield University, MK43 0AL, UK
}

\begin{abstract}
An ultra precision large optics grinding machine, $\mathrm{BoX}^{\circledR}$, was developed and produced at Cranfield University. BoX ${ }^{\circledR}$ offers a rapid and economic solution for grinding large off-axis aspherical and free-form optical components. Grinding high accuracy surfaces with low subsurface damage reduces subsequent polishing time. This efficient grinding process provides the capacity to grind $1.5 \mathrm{~m}$ parts. This paper presents an analysis of Astrositall ${ }^{\circledR}$ optical ground parts: a hexagonal $84 \mathrm{~m}$ radius of curvature mirror of $1 \mathrm{~m}$ across corners and an off-axis $350 \mathrm{~mm}$ diameter mirror. The $1 \mathrm{~m}$ hexagonal part is representative of segments under study for making extremely large telescope (ELT) segmented mirrors. The second part was machined off-axis to demonstrate free-form fabrication capability. These operations demonstrate the scalability of the rapid grinding process developed for large free-form optics. The use of an error compensation procedure improved an initial ground form accuracy to $+/-1 \mu \mathrm{m}$ p-v over 1 metre surface. The results highlighted the effect of grinding parameters and machine dynamics on form accuracy and fabrication time.
\end{abstract}

Keywords: Optics, Grinding, Subsurface damage, error compensation, Machine dynamics

\section{INTRODUCTION AND BACKGROUND}

In the past few years, the next generation of Extremely Large Telescopes (ELT) have evolved from concept studies (OWL, Euro50...) to advanced feasibility studies. Current developments are the Giant Magellan Telescope (GMT), the Thirty Meter Telescope (TMT) and the European Extremely Large Telescope (E-ELT) ${ }^{1,2,3}$. These projects demand many hundreds of large off-axis mirrors in the range of 1-2 metre dimension. Segments are made in low thermal expansion glass or glass ceramics such as ULE $^{\circledR}$, Zerodur ${ }^{\circledR}$, Astrositall ${ }^{\circledR}$ or Clearceram ${ }^{\circledR}$. These materials have previously been successfully used for large astronomical mirrors ${ }^{4}$.

The E-ELT project will have a $42 \mathrm{~m}$ telescope primary mirror comprising 906 hexagonal segments each of $1.45 \mathrm{~m}$ size ${ }^{5}$. With a completion target of 2018, this requires an improvement of current state-of-the-art fabrication process chains; which beginning with a preformed blank use successively grinding, lapping and iterative polishing processes. When scaled to the E-ELT demand, this total manufacturing time needs reducing by an order of magnitude. To reduce the manufacturing time for large mirrors, a UK-based research initiative "Basic Technologies - Ultra Precision Surfaces" was established ${ }^{6,7}$. A potential improvement was identified to shorten the total manufacturing time. A rapid low-damage precision grinding process ${ }^{8}$ can eliminate the lapping process and minimise subsequent polishing process. This grinding operation reduces form accuracy from millimetres to micrometre accuracy in combination with low subsurface damage depth. Subsequent polishing iterations ${ }^{9}$ achieve the final form accuracy more rapidly, leading to an effective integrated fabrication process chain as described in Figure 1.

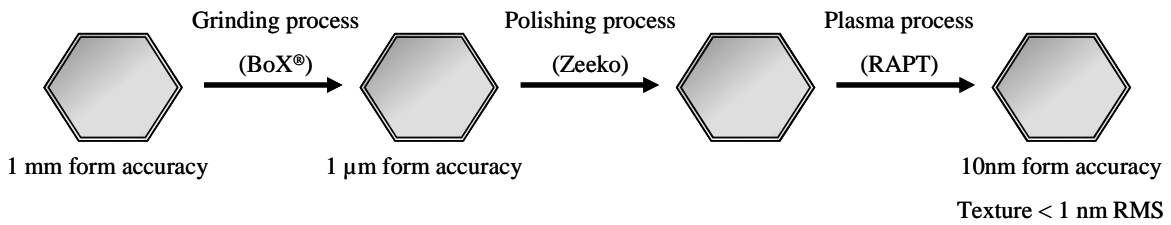

Figure 1: UPS ${ }^{2}$ IKC process chain for manufacturing of large optics 
To develop such an efficient grinding process, the Cranfield BoX grinding machine ${ }^{8}$ was designed and built (see section 2). Using the BoX machine, a precision grinding process was implemented on different grinding materials such as ULE, Zerodur, Fused silica and Silicon Carbide. The selected precision grinding stage uses a three stage grinding process. High removal rates (up to $187.5 \mathrm{~mm}^{3} / \mathrm{s}$ ) were achieved. This three stage process corresponds to a process time of 10 hours for a $1 \mathrm{~m}$ surface removing over $0.5 \mathrm{~mm}$. The form accuracy achieved was $+/-1 \mu \mathrm{m}$ p-v over a metre. Low subsurface damage depths between 5-10 $\mu \mathrm{m}$ were measured for ULE and Zerodur. Surface roughness $\left(\mathrm{R}_{\mathrm{a}}\right)$ values measured were between $100-200 \mathrm{~nm}^{10}$.

The Ultra Precision and Structured Surfaces ${ }^{11}$ (UPS $^{2}$ IKC) collaboration was set up capitalising on this UPS process chain for manufacturing of large optics. The UPS ${ }^{2}$ IKC capability is based in two temperature controlled laboratories: the Loxham Hexagon laboratory at Cranfield University, England and the Ultra Precision Surfaces (UPS) laboratory at Technium OpTIC, North Wales. A consortium was awarded an ESO feasibility study contract for delivering seven hexagonal segments of $1.45 \mathrm{~m}$ across corners. Cranfield University Precision Engineering is responsible for grinding these aspherical segments close to final form, from blanks rough ground to an $84 \mathrm{~m}$ base radius of curvature (ROC) spherical rough shape. This paper reports on the rapid grinding of aspherical segments and the BoX machine's form error compensation and freeform surface capability.

\section{CRANFIELD BOX GRINDING MACHINE}

The Cranfield BoX grinding machine was designed for manufacturing high precision low slope freeform surfaces ${ }^{8,12}$. This machine takes precision design concepts from large diamond turning and grinding machines combined with a dedicated grinding process. The BoX machine was designed with high static and dynamic loop stiffness in order to achieve low and controlled subsurface damage depth. Precision grinding was obtained using repeatable motions with micron-level accuracy error compensation.

Figure 2 shows the machine with a 1.5 metres capacity configuration used to service the ESO project.
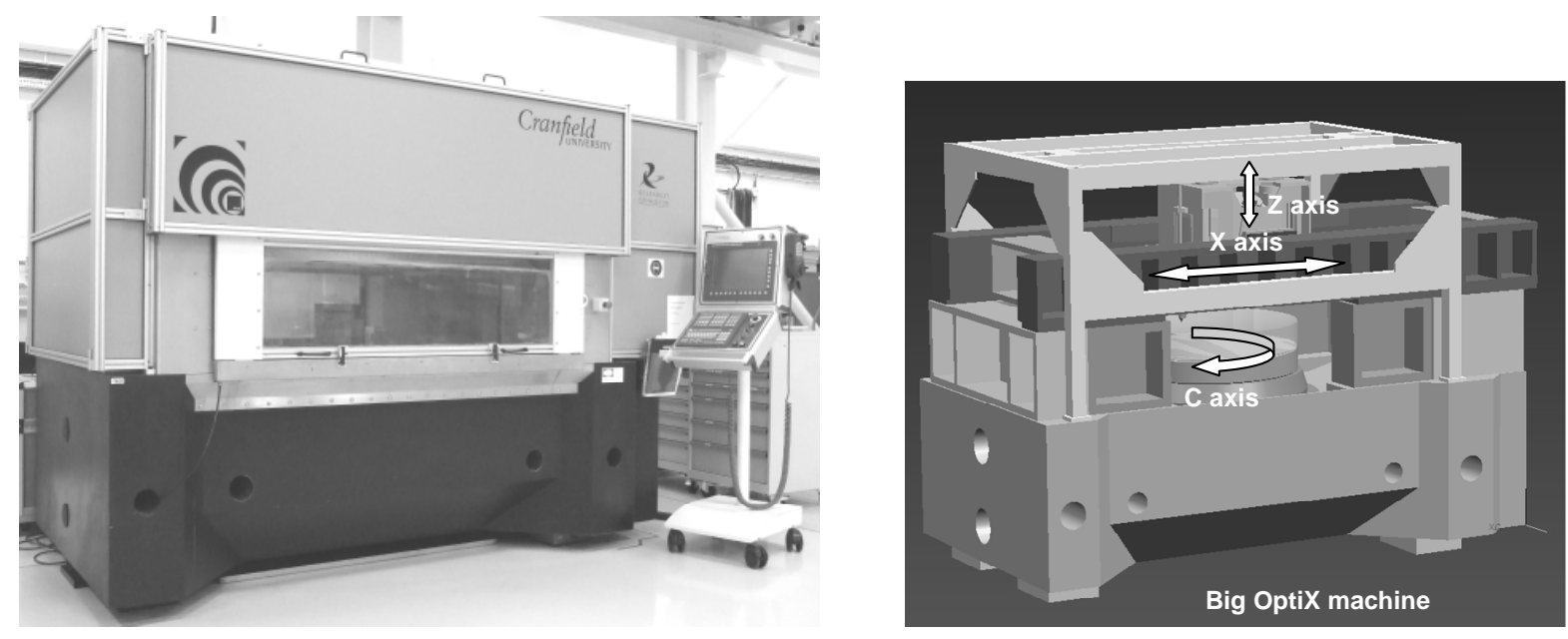

Figure 2: BoX grinding machine -1.5 m capacity

As part of a low cost manufacturing process, the BoX machine is based on a dedicated compact design for large off-axis mirrors in the range of 1-2 metres size. While maintaining high form accuracy, the BoX machine was designed for rapid grinding and a relatively low cost grinding process. Compared to other grinding machines such as the OAGM 2500, the BoX machine weighs ten times less (12 tonnes) and its overall footprint for a $2 \mathrm{~m}$ capacity is very compact $(3.2 \mathrm{~m} \times 2.1$ $\mathrm{m} \times 1.8 \mathrm{~m})$.

The machine uses a three axis $\mathrm{X}, \mathrm{Z}$ theta compact configuration. High dynamic loop stiffness is achieved through a minimum count (three) of axis motions and low moving mass. The $\mathrm{Z}$ axis is made of aluminium attaining below $750 \mathrm{~kg}$ moving mass for the $\mathrm{X}$ motion. High static loop stiffness is obtained with high stiffness hydrostatic bearings, minimum 
cantilever and minimum number of interfaces. $\mathrm{X}$ and $\mathrm{Z}$ axes are stacked to minimize possible cantilever length. Based on FEA analyses, the first structural mode is above $106 \mathrm{~Hz}$ ( $2 \mathrm{~m}$ capacity).

The machine's thermal stability is essential to obtaining accuracy and repeatability of the grinding process over ten hours. Slow moving heat sources (grinding spindle and linear motors) effects are reduced using high diffusivity materials. To prevent thermal creep, grating encoders are made of Zerodur low expansion glass. In addition, active feedback and feed forward temperature control is employed for the grinding spindle and linear bearings oil. The exit temperature of hydrostatic oils is maintained to within +/- 0.1 degree $\mathrm{C}$. Temperature control for linear and rotary motors and grinding coolant are also provided to a similar level.

The metrology frame and post process surface metrology are shown in Figure 3.

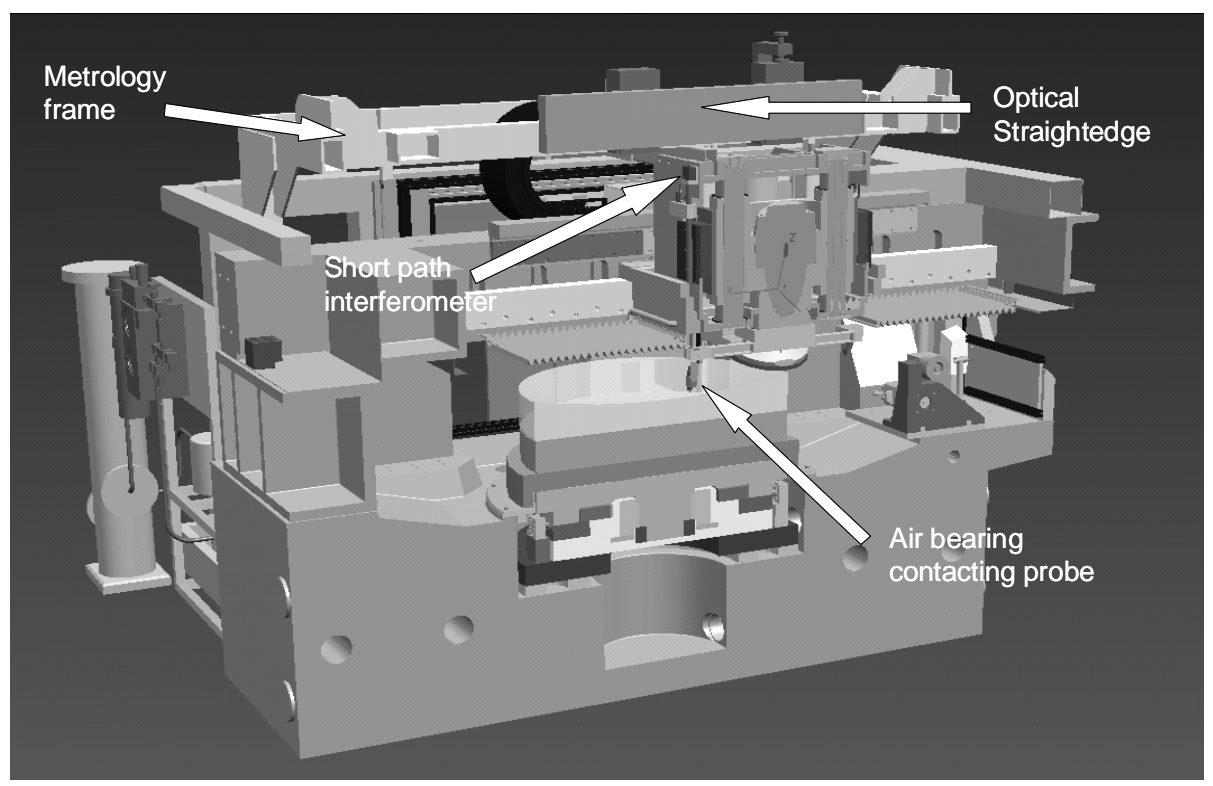

Figure 3: BoX metrology frame

The metrology frame is supported directly from the machine base and is independent of the axis motions. This nonstressed metrology frame is composed of an optical straightedge, a small short beam path interferometer and a low contact force short-stroke LVDT probe. The interferometer is mounted on an invar support rod which holds the LVDT probe. During the post-process surface metrology operation, the LVDT probe contacts with the workpiece and is kept close to its zero position at all time. The distance between the laser interferometer and the optical straightedge gives the workpiece measurement. This LVDT probe is also used to obtain the workpiece position in space, relative to grinding motions. Fixed datum points are positioned on the holding fixture to transfer coordinates between grinding machine and any subsequent off-machine metrology (or subsequent processes). A second LVDT probe is used to measure the grinding wheel form imprinted onto the dressing sticks in order to error compensate the grinding wheel shape form error.

\section{PRECISION GRINDING PROCESS CHAIN}

The machine axes configuration leads to a modified R-theta grinding mode. The inclined grinding wheel has an approximately toric shaped abrasive layer. Therefore, the grinding contact point moves along the grinding wheel shape depending on local surface slope of the optical form. The CNC program accommodates for this effect on curved and complex surfaces. The control of the $\mathrm{Z}$ axis precision motion and $\mathrm{C}$ axis variable rotation speed requires a large quantity of data points. Its Fanuc 30i CNC control system uses Nurbs functions to reduce amount of programming lines.

A three stage grinding process including rough, semi-finish and finish cuts was chosen ${ }^{10}$. They used $76 \mu \mathrm{m}, 46 \mu \mathrm{m}$ and $25 \mu \mathrm{m}$ diamond grit size respectively. Resin bonded grinding wheels were selected. Each stage generated form accuracy 
and subsurface damage depth that were significantly improved by the subsequent grinding stage. Constant surface speed is maintained for constant grinding forces through the grinding process.

The grinding wheel abrasive layer contributes to the overall workpiece form accuracy. A forming station is integrated in the machine and the form is periodically checked using integrated wheel form metrology. The grinding wheel is plunged against the forming wheel along $\mathrm{Z}$ axis to set depth and back and forward movement along $\mathrm{X}$ axis are used to form the grinding wheel shape. A dressing unit is used to obtain sharp abrasive grains after the forming operation.

Following development grinding, the following rapid precision grinding process chain is proposed for $1.45 \mathrm{~m}$ aspherical segments as shown in Figure 4.
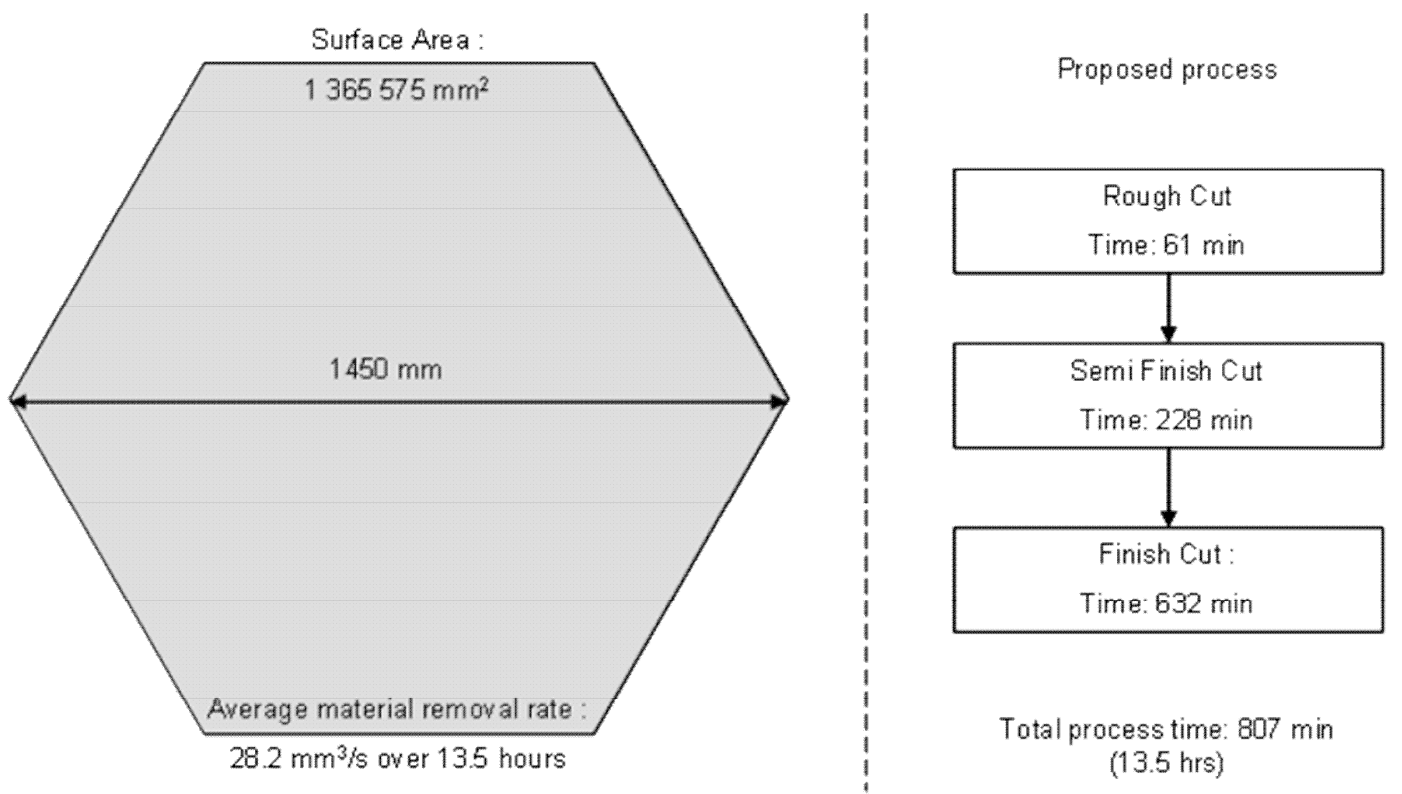

Figure 4: Grinding stages for manufacturing of large optics ${ }^{10}$

Based on a total depth of material removed of $1 \mathrm{~mm}$, process time is 13.5 hours for a $1.45 \mathrm{~m}$ segment. The targeted surface accuracy $\left(\mathrm{P}_{\mathrm{t}}\right)$ and surface roughness $\left(\mathrm{R}_{\mathrm{a}}\right)$ are $3 \mu \mathrm{m} \mathrm{p}-\mathrm{v}$ (full aperture) and $200 \mathrm{~nm}$ respectively. This final cut includes the error compensation algorithm and relies on a highly repeatable grinding machine and process chain. The amount of material depth expected to be polished out is therefore a maximum of $13 \mu \mathrm{m}$ with an expected subsurface damage depth below $10 \mu \mathrm{m}$.

In order to achieve a highly efficient grinding process with minimum manufacturing downtime, a rapid segment loading/unloading operation is required. A loading system using ball bearings and steel rails was designed to accommodate the up to $1.5 \mathrm{~m}$ holding fixture employed. This loading system is integrated within the grinding machine to minimise setting time. Figure 5 shows the loading system and the $1.5 \mathrm{~m}$ holding fixture. 


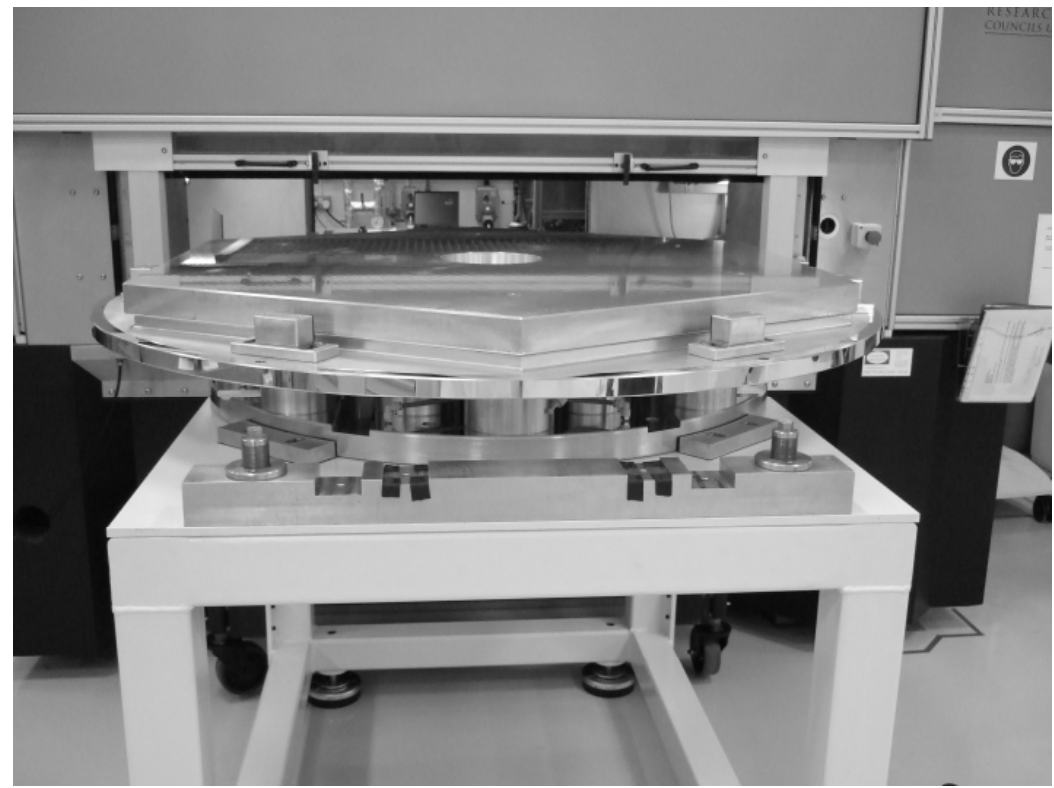

Figure 5: Holding fixture and loading system

The grinding holding fixture is employed to support the segment within reach of the $\mathrm{Z}$ axis motion. It is made of high grade aluminium, diamond turned flat and parallel. Reference surfaces and clocking rings are diamond turned to help position inside the grinding machine. The precise positioning of the workpiece is done with reference to micron precision balls that are measured on a large-scale CMM and again inside the BoX machine using the in-situ metrology frame and system. This allows transfer of coordinates between the machines and spatial position of the workpiece relative to the grinding motions.

\section{RESULTS AND DISCUSSION}

Two Astrositall parts were ground in preparation for $1.5 \mathrm{~m}$ freeform optics. A $1 \mathrm{~m}$ hexagonal concave part and a $350 \mathrm{~mm}$ off-axis spherical part were chosen.

\subsection{Material properties}

SITALL CO-115 $\mathrm{M}^{13}$ (Astrositall $^{\circledR}$ ) is a crystalline glass material (glass ceramics) having an ultra-low coefficient of thermal expansion manufactured by JSC LZOS in Russia. Its mechanical properties are close to other low thermal expansion materials such as Zerodur and Clearceram. The material properties for Zerodur, ULE and Clearceram are included for comparison, in Table 1.

Table 1: Optical materials properties ${ }^{13,14,15}$

\begin{tabular}{|c|c|c|c|c|}
\hline & $\begin{array}{c}\text { Density } \\
(\mathrm{g} / \mathrm{cm} 3)\end{array}$ & $\begin{array}{c}\text { Elastic Modulus } \\
(\mathrm{GPa})\end{array}$ & $\begin{array}{c}\text { Micro hardness } \\
(\mathrm{GPa})\end{array}$ & $\begin{array}{c}\text { CTE } \\
(10-6 / \mathrm{K})\end{array}$ \\
\hline Astrositall & 2.46 & 92 & 7.86 & 0.02 \\
\hline Zerodur & 2.52 & 91 & 6.2 & 0.05 \\
\hline ULE & 2.2 & 70 & 4.6 & 0.025 \\
\hline Clearceram & 2.55 & 90 & 6.4 & 0.04 \\
\hline
\end{tabular}




\subsection{Error compensation capability}

A $1 \mathrm{~m}$ across corner hexagonal Astrositall segment with a thickness of $53 \mathrm{~mm}$ was ground. It was received ground to 84 $\mathrm{m}+/-3 \mathrm{~m}$ radius of curvature spherical shape. The aim was to improve the form accuracy using our grinding process. In order to minimise the number of grinding operations and setting time, one resin bonded grinding wheel was used. A D25 grinding wheel was selected to achieve adequate surface roughness quality and subsurface damage depth. The grinding wheel was trued to shape, balanced and dressed before the finish cut.

After the finish cut of $50 \mu \mathrm{m}$ depth of cut (390 min), the part was unloaded and measured on its holding fixture using a Large-scale CMM, generating a series of linear surface profile scans. Those data (after filtering) were used to generate the error compensated NC program. The part was reloaded and ground again using a semi finish cut and a finish cut. The error compensation was applied to the finish cut. A scan measurement of the $1 \mathrm{~m}$ Astrositall part after final finish grind is shown in Figure 6.

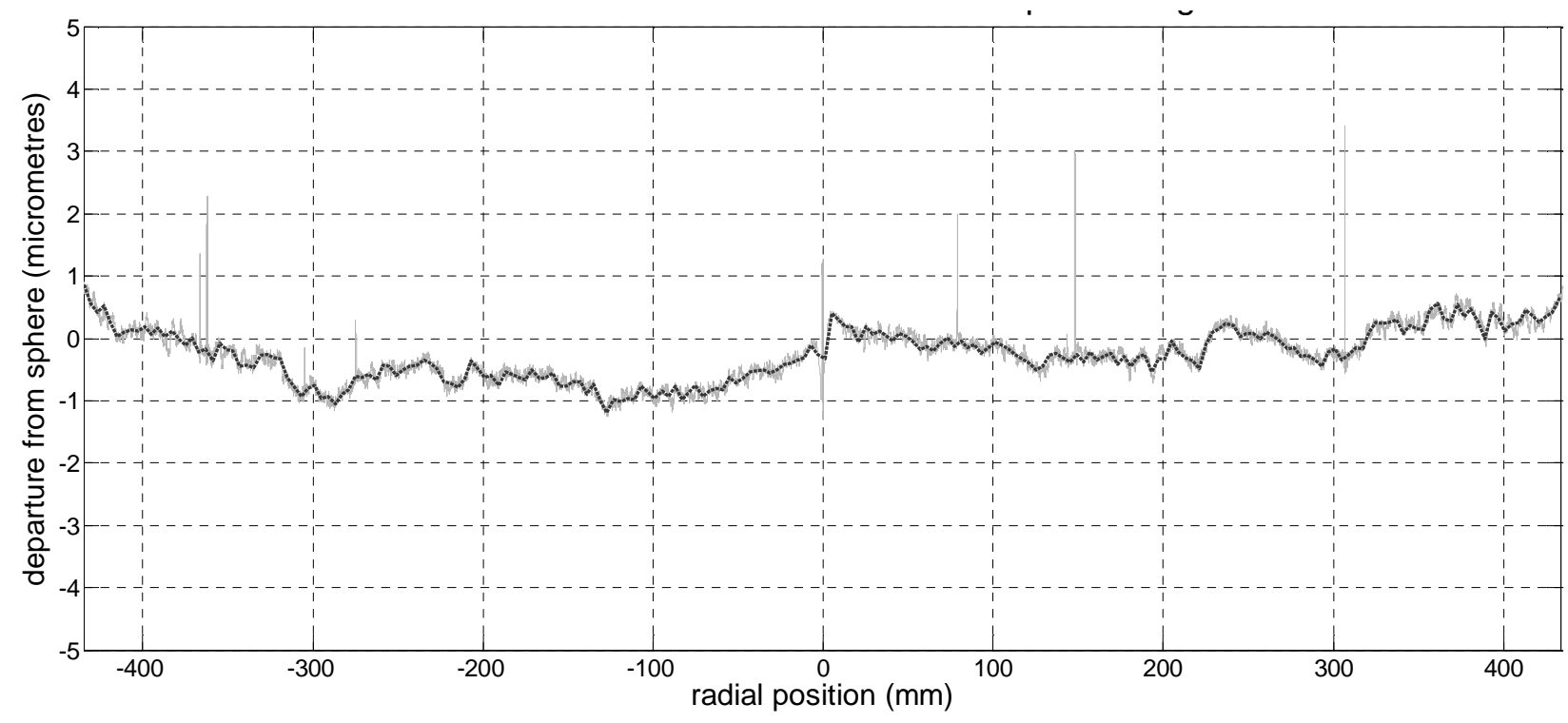

Figure 6: Scan measurement of $1 \mathrm{~m}$ Astrositall part after grinding

Results show ground surface in compensated mode. The data was fitted using a fixed $84 \mathrm{~m}$ radius sphere, as this is the designed shape. Surface form accuracy achieved is below $2 \mu \mathrm{m}$ p-v. The combined grinding and metrology process shows a good level of repeatability as evidenced by the compensation achievements. A filter was applied again on the final ground surface in order to represent what will be seen after flash polishing using the optical tower. This is based on the pixel size accuracy of the 4D interferometer used and is shown with the dashed line in the figure.

Peak to valley $\left(\mathrm{P}_{\mathrm{t}}\right)$ results, in term of spatial wavelength, were defined to reduce the amount of subsequent polishing operations required. Those spatial wavelength values were selected based on development on a $1 \mathrm{~m}$ Zerodur hexagonal part previously reported. The overall form accuracy obtained is below $2 \mu \mathrm{m}$ over a metre. Similar amplitude is achieved down to $50 \mathrm{~mm}$ spatial wavelength. Those errors can be related to thermal errors, motions errors and non-repeatable measurement errors. Between $50 \mathrm{~mm}$ and $2 \mathrm{~mm}$, Pt reduces to $1.57 \mu \mathrm{m}$. Below $2 \mathrm{~mm}$, the form accuracy is governed by the cusping generated by the grinding mode employed. These results demonstrate grinding accuracy and efficient grinding process time. This validates the use of error compensation to improve the final grinding form accuracy.

\subsection{Freeform surface capability}

A $350 \mathrm{~mm}$ diameter optic with $3.2 \mathrm{~m}$ ROC and $60 \mathrm{~mm}$ thick was selected. This grinding operation was used to demonstrate freeform surface capability. The holding fixture was placed central to $\mathrm{C}$ axis. The part was positioned on the holding fixture, off centre by $19.2 \mathrm{~mm}$ as shown in Figure 7. Therefore, the rotation axis is different from the part centre. 
While mounted $19.2 \mathrm{~mm}$ off-axis, the vertical Z-axis needs to move by more than $0.5 \mathrm{~mm}$ during grinding within one rotation of the part.

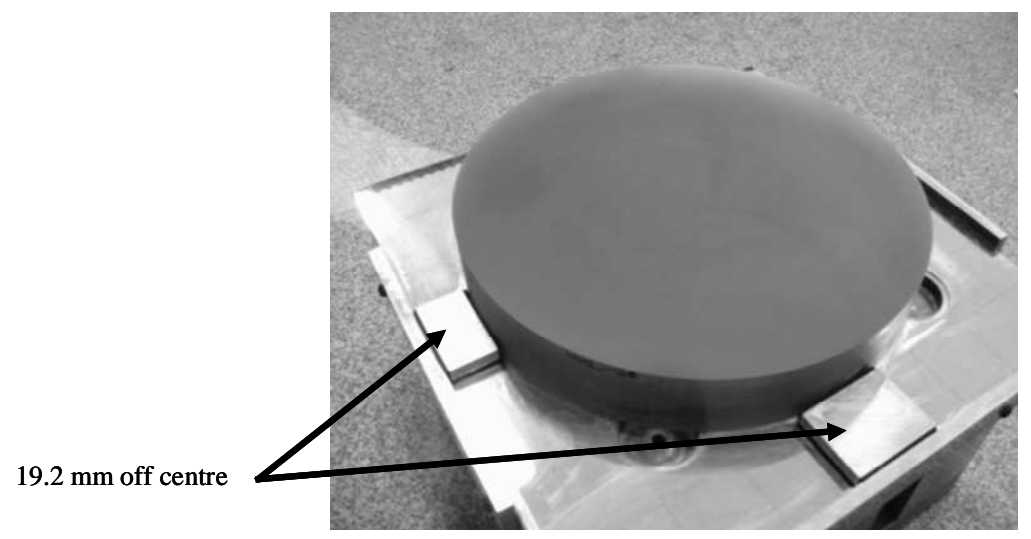

Figure 7: $350 \mathrm{~mm}$ Astrositall part

The part was ground to $2.9 \mathrm{~m}$ R.O.C. using a similar grinding process strategy to that described in section 5.2. A D25 resin bonded grinding wheel using same grinding speeds as described in section 4.2 was employed. After a first finish cut, the part was measured and error compensation was applied. Results of the finish cut with error compensation are shown in Figure 8.

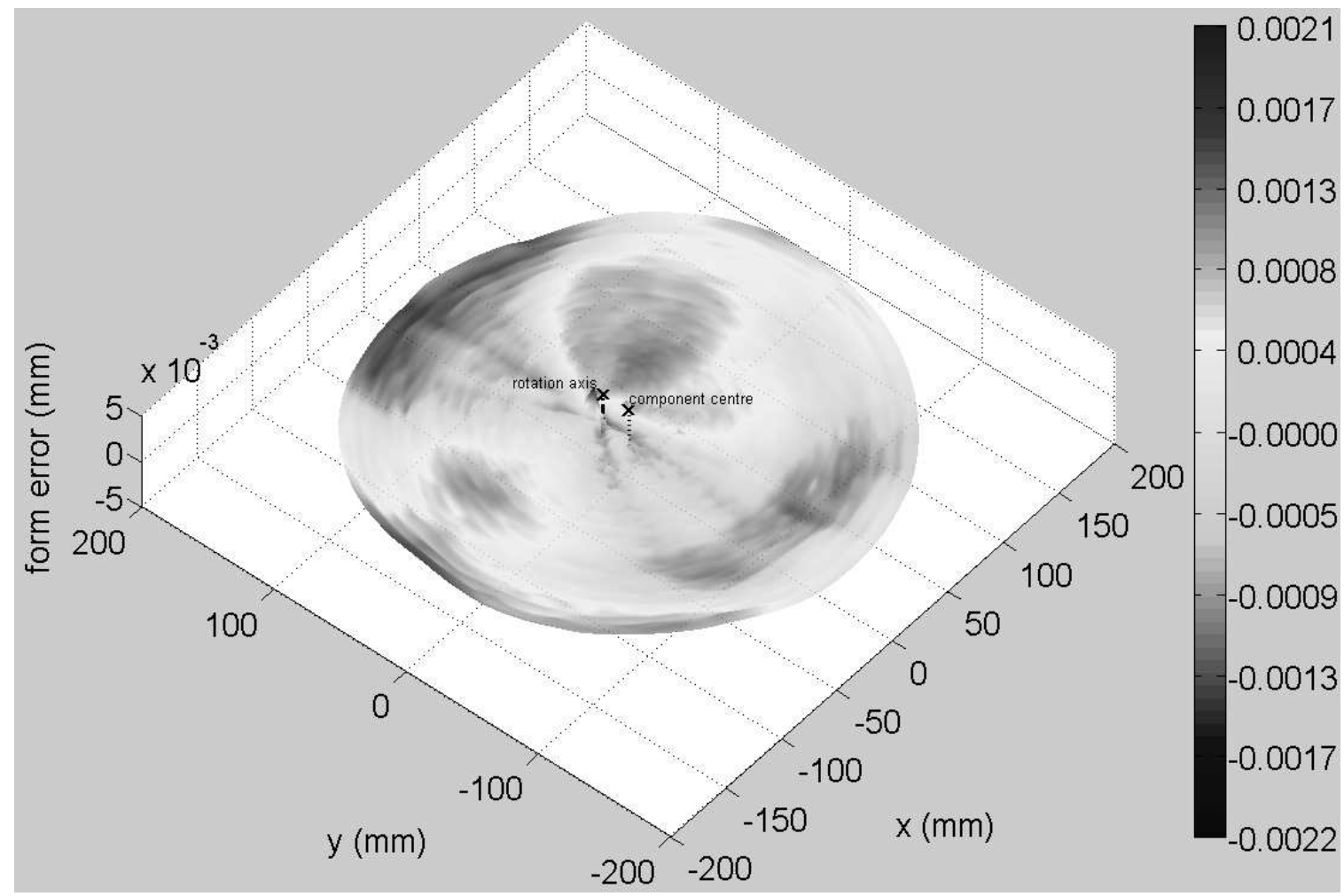

Figure 8: Form departure from specified $2.9 \mathrm{~m}$ ROC sphere, ground $19.2 \mathrm{~mm}$ off-centre

Those data were collected using the large scale CMM. The total form accuracy is 4 microns p-v for a highly free-form part. The $\mathrm{P}_{\mathrm{t}}$ amplitude over a $20-50 \mathrm{~mm}$ wavelength is restricted below $300 \mathrm{~nm}$ radially and far less circumferentially. 
This corresponds to performance currently achieved on the Cranfield BoX on much larger components. Results demonstrate the capability to make free-form surfaces.

\section{CONCLUSIONS}

A novel ultra precision grinding machine design has been established for the rapid production of large-sized 'free-form' surfaces of low slope. It is highly compact with a footprint around one sixth that of previous designs (machine, control and services); its mass is around one tenth. Its fabrication rate is ten times faster than the currently reported state-of-theart, at the same time possessing low subsurface damage and high accuracy. This paper showed that the $1.5 \mathrm{~m}$ capacity BoX machine has error compensation and freeform capabilities. It delivers the required form accuracy for ESO $1.45 \mathrm{~m}$ hexagonal aspheric segments based on high repeatability of the grinding process parameters and grinding machine motions. Production of the $1.45 \mathrm{~m}$ segment is underway with a rapid grinding process time target of 13.5 hours.

\section{ACKNOWLEDGEMENTS}

The authors gratefully acknowledge both funding support from the McKeown Precision Engineering and Nanotechnology Foundation at Cranfield and project funding through the UK's Joint Research Councils' - Basic Technologies programme and EPSRC funded Integrated Knowledge Centre for UPS ${ }^{2}$.

\section{REFERENCES}

[1] TMT project, http://www.tmt.org/ - accessed 06/10.

[2] GMT project, www.gmto.org/ - accessed 06/10.

[3] E-ELT project, http://www.eso.org/public/teles-instr/e-elt.html - accessed 06/10.

[4] Gilmozzi, R., "Science and technology drivers for future giant telescopes," Proc. SPIE 5489, 1-10 (2004).

[5] Gilmozzi, R. and Spyromilio, J., "The European Extremely Large Telescope (E-ELT)," ESO Messenger 127, 11-19 (2007).

[6] Shore, P.; "Large Optics Manufacturing study (LOMS)" Final Report, Cranfield University (2003).

[7] Shore, P. and May-Miller, R., "Production Challenge of the Optical Segments for Extra Large Telescopes,"

Proc Int. Workshop On Extreme Optics And Sensors 40, 25 (2003).

[8] Shore, P., Morantz, P., Luo, X., Tonnellier, X.and Read, R., and May-Miller, R., "Design philosophy of the ultra precision big optix BoX machine,” Proc. Landamap Conf., 200-209 (2005).

[9] Walker, D., Beaucamp, A. T., Brooks, D., King, A., Morton, R., and McCavana, G., "New polishing technology for large mirrors and lenses,"Proc. SPIE TD02, 31-35 (2003).

[10] Tonnellier X., "Precision machining of large freeform optics", PhD Thesis, Cranfield University (2009).

[11] UPS2-IKC, http://www.ups2.co.uk - accessed 06/10.

[12] Shore, P., Luo, X., Jin, T., Tonnellier, X., Morantz, P., Stephenson, D., Collins, R., Roberts, A., May-Miller,

R., and Read, R., "Grinding mode of the BOX ultra precision free-form grinder," Proceedings of ASPE (2005).

[13] Astrositall, http://lzos.ru/en/index.php?option=com_content\&task=view\&id=6 - accessed 06/10.

[14] Matson, L. "CTE Tailored Materials for Hybrid Mirror Systems," SOMTC Technology days, (2003).

[15] Viens, M., "Fracture Toughness and Crack Growth of Zerodur," Technical Memo (1990). 